\title{
Plasma fibrinogen and serum albumin levels (FA score) act as a promising prognostic indicator in non-small cell lung cancer
}

This article was published in the following Dove Press journal:

OncoTargets and Therapy

21 June 2017

Number of times this article has been viewed

\author{
Pengxiang Chen' \\ Cong Wang' \\ Bo Cheng ${ }^{2}$ \\ Effat Un Nesa' \\ Yuan Liu' \\ Yibin Jia' \\ Yan Qu' \\ Ziying Jiang' \\ Jie $\mathrm{Han}^{3}$ \\ Yufeng Cheng' \\ 'Department of Radiation Oncology, \\ Qilu Hospital of Shandong \\ University, Jinan, ${ }^{2}$ Medical College \\ of Qingdao University, Qingdao, \\ ${ }^{3}$ Department of Radiation Oncology, \\ Shandong Cancer Hospital and \\ Institute, Shandong University, Jinan, \\ People's Republic of China
}

Correspondence: Yufeng Cheng

Department of Radiation Oncology,

Qilu Hospital of Shandong University,

107 West Wenhua Road, Jinan, 2500I2,

People's Republic of China

Tel +86I8769785399

Email qlcyf123@I63.com
Background: Evidence implies that preoperative plasma fibrinogen and serum albumin are associated with cancer prognosis. We aimed to explore the prognostic values of the score based on plasma fibrinogen and serum albumin levels (FA score) in non-small cell lung cancer (NSCLC), and to compare that with prognostic nutritional index (PNI).

Patients and methods: In all, 182 patients pathologically diagnosed with NSCLC were included in this study. Kaplan-Meier survival analysis and multivariate analysis were used in the prognostic analyses.

Results: High FA score was related to smoking $(P=0.005)$, poor differential grade $(P=0.002)$, and advanced T stage $(P<0.001)$ and tumor, node, and metastases stage $(P=0.011)$. Low PNI showed association with advanced $\mathrm{T}$ stage $(P=0.030)$. Kaplan-Meier survival analysis indicated that high FA score and low PNI were associated with poor progression-free survival (PFS; for the FA score, $P<0.001$; for PNI, $P=0.001$ ) and overall survival (OS; for the FA score, $P<0.001$; for PNI, $P=0.013)$, respectively. Multivariate analysis revealed that FA score was an independent predictor for PFS $(P=0.003)$ and OS $(P=0.001)$ in NSCLC patients.

Conclusion: The FA score could act as a more promising prognostic predictor than PNI in NSCLC patients who underwent pneumonectomy.

Keywords: non-small cell lung cancer, surgical treatment, serum albumin, plasma fibrinogen, prognostic nutritional index, prognosis

\section{Introduction}

In 2012, 1.8 million newly diagnosed lung cancer patients were estimated to be affected worldwide which accounted for $\sim 13 \%$ of all types of cancer diagnoses. And, lung cancer ranked as the leading cause of cancer death among males in 2012. ${ }^{1}$ Although much progress in multimodal therapy has emerged, surgical resection continues to play a vital role in the treatment of lung cancer, especially the relatively early nonsmall cell lung cancer (NSCLC). However, the 5-year survival rate of lung cancer patients still remains only $\sim 17.4 \%$ when various therapies are adopted..$^{2,3}$ Therefore, it is necessary to develop effective biomarkers to identify patients who may have poor clinical outcomes after surgical treatment.

Some indicators, including hemostatic factors, nutritional status, and immunological responses, could reflect outcomes of patients with tumors. ${ }^{4-6}$ Fibrinogen, produced in the liver in response to cytokine stimulation, may reflect tumor development and inflammatory level. ${ }^{7-9}$ Several studies confirmed the relationship between high serum fibrinogen levels and poor prognosis in NSCLC patients. ${ }^{10-12}$ Albumin, which reflects nutritional status, is also reported to have a strong association with outcomes of 
NSCLC patients. ${ }^{13,14}$ Therefore, the combination of fibrinogen and albumin may serve as a more effective scoring system to predict prognosis of NSCLC patients following pneumonectomy. Satoru Matsuda et al reported that plasma fibrinogen and serum albumin levels (FA score) showed significant association with survival in esophageal cancer patients. ${ }^{15}$

The prognostic nutritional index (PNI), which is calculated by albumin and lymphocytes count, has been assessed as a prognostic indicator in tumors, such as esophageal cancer, gastric cancer, and hepatocellular carcinoma. ${ }^{6,16,17}$ It is broadly demonstrated that high preoperative PNI is related to normal preoperative carcinoembryonic antigen level, small tumor size, well differential grade, pathological stage I, and long survival time in NSCLC patients. ${ }^{18-21}$ However, to the best of our knowledge, no study has investigated FA score in NSCLC patients.

Thus, we conducted a retrospective study to mainly discuss correlations of preoperative FA score with clinicopathological characteristics and survival outcomes in NSCLC patients. Then, we compared the values of FA score and PNI in terms of progression-free survival (PFS) and overall survival (OS).

\section{Materials and methods Patients}

Between January 2009 and December 2010, 182 patients with pathologically diagnosed NSCLC who underwent pneumonectomy at the Department of Thoracic Surgery, Qilu Hospital of Shandong University were retrospectively reviewed in our cohort. Patients were excluded from our research if they: 1) underwent neoadjuvant therapy; 2) had $\geq 2$ primary tumors; 3) had coagulation disorders or metabolic diseases before; 4) were lost to follow-up. All clinicopathological features were obtained from the patients' records. Pathological stages of patients were based on the tumor, node, and metastases (TNM) classification of the American Joint Committee on Cancer staging manual (seventh edition, 2010). ${ }^{43}$ Patients' laboratory and hematological data were tested routinely within 1 week prior to surgery. All clinical investigations in our study were conducted in accordance with the Declaration of Helsinki. This study was ratified by the Ethics Committee of Qilu Hospital of Shandong University. Written informed consent was obtained from all the patients in this study.

\section{Follow-up}

Patients were followed up every 3-4 months in the first 2 years after surgery and every 6 months thereafter until they were lost or dead. The last date of follow-up was November 2015. Follow-up of patients included blood tests, urine tests, computed tomography, and physical examination. PFS and OS at the end of our follow-up were adopted as the endpoints of this study. PFS (in months) was the time interval during which no local recurrence or distant metastasis occurred in patients. OS (in months) was calculated as the time interval from the date of completion of surgery to the date of death or last follow-up.

\section{FA score and $\mathrm{PNI}$ evaluation}

From receiver operating characteristic (ROC) curve analysis, cutoff values of fibrinogen and albumin were determined. Then, fibrinogen and albumin acted as categorical variables in this study. Patients with both elevated fibrinogen and decreased albumin were assigned a score of 2 , patients with either of the two abnormities were assigned a score of 1 , while those with neither of the two abnormities were assigned a score of 0 . PNI was obtained by albumin $(\mathrm{g} / \mathrm{L})+5 \times$ total lymphocyte count $\left(10^{9} / \mathrm{L}\right)$.

\section{Statistical analysis}

Serum fibrinogen, serum albumin, and lymphocyte count were calculated as mean and standard deviation. The three indicators were analyzed across differential grade, $\mathrm{T}$ stage, $\mathrm{N}$ stage, and TNM classification. An unpaired $t$-test and oneway analysis of variance were adopted to analyze continuous variables of different subgroups. Relationships between categorical variables were assessed using Fisher's exact test or Pearson's chi-square test. ROC analysis was performed to determine possible cutoff values of the continuous serum fibrinogen, albumin, and PNI. To confirm the accuracy of the FA score and PNI for predicting survival outcomes, ROC curves were also used during the analyses. In the analyses of PFS and OS, Kaplan-Meier method and log-rank tests were used. The Cox proportional hazards regression model was adopted in the univariate and multivariate analyses. Variables with statistical significance in the univariate analysis could be included into the multivariable analysis. A two-sided $P$-value was used in this study and a value $<0.05$ was considered statistically significant. The Statistical Package for Social Sciences (SPSS for Windows, version 20.0; IBM Corporation, Armonk, NY, USA) program was used for statistical analyses.

\section{Results}

\section{Baseline clinicopathological characteristics of patients}

The baseline characteristics of 182 patients are shown in Table 1. Fifty five $(30.2 \%)$ female patients and 127 $(69.8 \%)$ male patients were included. The age of patients at 
Table I Clinical and histopathological characteristics of I 82 nonsmall cell lung cancer patients

\begin{tabular}{|c|c|}
\hline Characteristic & Patients, n (\%) \\
\hline \multicolumn{2}{|l|}{ Sex } \\
\hline Female/male & $55(30.2) / 127(69.8)$ \\
\hline \multicolumn{2}{|l|}{ Age (years) } \\
\hline Mean \pm SD & $60.85 \pm 10.08$ \\
\hline Median (range) & $62(29-85)$ \\
\hline \multicolumn{2}{|l|}{ Smoking } \\
\hline Yes & $83(45.6)$ \\
\hline No & $99(54.4)$ \\
\hline \multicolumn{2}{|l|}{ Histologic type } \\
\hline SCC & $72(39.6)$ \\
\hline$A D C$ & $75(4 \mid .2)$ \\
\hline Others & $35(19.2)$ \\
\hline \multicolumn{2}{|l|}{ Differential grade } \\
\hline Poor & $21(11.5)$ \\
\hline Middle & $95(52.2)$ \\
\hline Well & $66(36.3)$ \\
\hline \multicolumn{2}{|l|}{ T stage } \\
\hline TI & $72(39.5)$ \\
\hline $\mathrm{T} 2$ & $82(45.1)$ \\
\hline T3 & $28(15.4)$ \\
\hline \multicolumn{2}{|l|}{$N$ stage } \\
\hline No & $116(63.7)$ \\
\hline $\mathrm{NI}-3$ & $66(36.3)$ \\
\hline \multicolumn{2}{|l|}{ TNM stage } \\
\hline I & $94(51.6)$ \\
\hline II & $55(30.2)$ \\
\hline III & $33(18.2)$ \\
\hline \multicolumn{2}{|l|}{ Adjuvant therapy } \\
\hline Yes & $84(46.2)$ \\
\hline No & $98(53.8)$ \\
\hline \multicolumn{2}{|l|}{ Lymphocyte (10\%/L) } \\
\hline Mean \pm SD & $1.86 \pm 0.61$ \\
\hline Median (range) & I.8I (0.69-4.39) \\
\hline \multicolumn{2}{|l|}{ Albumin (g/L) } \\
\hline Mean \pm SD & $42.88 \pm 4.82$ \\
\hline Median (range) & $42.90(25.10-53.5)$ \\
\hline \multicolumn{2}{|l|}{ Fibrinogen $(\mathrm{g} / \mathrm{L})$} \\
\hline Mean \pm SD & $3.82 \pm 1.20$ \\
\hline Median (range) & $3.59(1.92-8.73)$ \\
\hline \multicolumn{2}{|l|}{$\mathrm{PNI}$} \\
\hline Mean \pm SD & $52.18 \pm 5.69$ \\
\hline Median (range) & $52.83(34.65-65.05)$ \\
\hline
\end{tabular}

Abbreviations: SD, standard deviation; SCC, squamous cell carcinoma; $A D C$ adenocarcinoma; PNI, prognostic nutritional index;TNM, tumor, node, and metastases.

diagnosis ranged from 29 to 85 years and the median was 62 years. Seventy two (39.6\%) patients had the histologic type of squamous cell carcinoma (SCC) while 75 (41.2\%) patients were diagnosed with adenocarcinoma (ADC). Other histologic types occurred in 35 (19.2\%) patients, including 12 cases of bronchioloalveolar carcinoma, 12 cases of adenosquamous carcinoma, seven cases of large cell carcinoma, and four cases of papillary ADC. Ninety eight (53.8\%) patients underwent pneumonectomy alone, 14 (7.7\%) patients received postoperative radiotherapy, 49 (26.9\%) received postoperative chemotherapy, and 21 (11.6\%) received postoperative chemoradiotherapy.

\section{Associations of preoperative lymphocyte count, serum albumin, fibrinogen, FA score, and PNI with clinicopathological characteristics}

The associations of serum albumin, fibrinogen, and lymphocyte count with clinical status are shown in Table 2. Lymphocyte count (for N stage, $P=0.029$; for TNM stage, $P=0.036$ ) decreased, and fibrinogen level (for $\mathrm{N}$ stage, $P=0.003$; for TNM stage, $P<0.001)$ increased with the advancement of $\mathrm{N}$ stage and TNM stage. Albumin (for the differential grade, $P=0.004$; for T stage, $P=0.012)$ and fibrinogen $(P<0.001)$ were both associated with differential grade and $\mathrm{T}$ stage. These three indices showed statistical relevance with TNM stage, especially fibrinogen. Fibrinogen was the only indicator associated with all of differential grade, $\mathrm{T}$ stage, lymph node metastasis, and TNM stage.

With ROC analysis, we obtained the cutoff value of $39.3 \mathrm{~g} / \mathrm{L}$ for serum albumin, $3.62 \mathrm{~g} / \mathrm{L}$ for fibrinogen, and 46.6 for PNI. Eighty four (46.2\%) patients were distributed to the group of score $0,67(36.8 \%)$ to the group of score 1 , and others were in the group of score 2. For PNI, 33 (18.1\%) patients were assigned to the lower group ( $<46.6)$, while 149 (81.9\%) patients were included in the higher group $(\geq 46.6)$.

Table 2 Clinical status and albumin, fibrinogen, and lymphocyte count in non-small cell lung cancer

\begin{tabular}{|c|c|c|c|c|c|c|}
\hline \multirow[t]{2}{*}{ Characteristics } & \multicolumn{2}{|c|}{$\begin{array}{l}\text { Albumin } \\
\text { (g/L) }\end{array}$} & \multicolumn{2}{|c|}{$\begin{array}{l}\text { Fibrinogen } \\
(\mathrm{g} / \mathrm{L})\end{array}$} & \multicolumn{2}{|c|}{$\begin{array}{l}\text { Lymphocyte } \\
\text { (10\%/L) }\end{array}$} \\
\hline & Mean & SD & Mean & SD & Mean & SD \\
\hline \multicolumn{7}{|l|}{ Differential grade } \\
\hline Poor & 39.63 & 4.14 & 5.04 & 1.68 & 1.68 & 0.55 \\
\hline Middle & 43.43 & 4.61 & 3.52 & 1.03 & 1.92 & 0.68 \\
\hline Well & 43.11 & 4.96 & 3.88 & 0.79 & 1.84 & 0.49 \\
\hline$P$-value & $0.004^{*}$ & & $<0.00 I^{*}$ & & 0.252 & \\
\hline \multicolumn{7}{|l|}{ T stage } \\
\hline TI & 43.67 & 4.56 & 3.29 & 0.75 & 1.84 & 0.63 \\
\hline $\mathrm{T} 2$ & 42.99 & 4.45 & 3.93 & 1.03 & 1.94 & 0.63 \\
\hline T3 & 40.51 & 5.81 & 4.90 & 1.74 & 1.66 & 0.44 \\
\hline$P$-value & $0.012^{*}$ & & $<0.00 I^{*}$ & & 0.107 & \\
\hline \multicolumn{7}{|l|}{$\mathrm{N}$ stage } \\
\hline No & 43.15 & 4.96 & 3.62 & 1.07 & 1.93 & 0.64 \\
\hline $\mathrm{NI}-3$ & 42.39 & 4.56 & 4.18 & 1.34 & 1.73 & 0.52 \\
\hline$P$-value & 0.314 & & $0.003 *$ & & $0.029 *$ & \\
\hline \multicolumn{7}{|l|}{ TNM stage } \\
\hline I & 43.43 & 4.60 & 3.48 & 0.95 & 1.95 & 0.67 \\
\hline II & 43.07 & 5.18 & 3.95 & 1.04 & 1.83 & 0.50 \\
\hline III & 40.96 & 4.42 & 4.60 & 1.65 & 1.64 & 0.52 \\
\hline$P$-value & $0.036^{*}$ & & $<0.00 I^{*}$ & & $0.036^{*}$ & \\
\hline
\end{tabular}

Note: *Statistically significant values, $P<0.05$.

Abbreviations: SD, standard deviation; TNM, tumor, node, and metastases. 
The relationships of FA score and PNI with clinicopathological characteristics are shown in Table 3. Significant differences occurred for smoking $(P=0.005)$, differential grade $(P=0.002), \mathrm{T}$ stage $(P<0.001)$, and TNM stage $(P=0.011)$ according to FA score. High FA score was related to poor differential grade, as well as advanced T and TNM stage. High PNI was related to early T stage of the tumor $(P=0.030)$, but no associations were found between PNI and other characteristics (all $P>0.05$ ).

\section{Predictive values of FA score and PNI for patients' survival}

At the end of follow-up, $86(47.3 \%)$ patients died. The median PFS was 47.0 months, ranging from 1.0 to 81.0 months. The median OS was 59.5 months, ranging from 2.3 to 81.0 months. Significant differences occurred for PFS $(P<0.001)$ and OS $(P<0.001)$ according to FA score (Figure 1). PFS $(P=0.001)$ and $\mathrm{OS}(P=0.013)$ of patients between low and high PNI groups also exhibited statistical difference. In conclusion, a high FA score, as well as low PNI, was associated with the short survival time of patients with NSCLC.

\section{Univariate and multivariate survival analyses}

Table 4 shows the results of univariate analysis of PFS and OS. The following factors were related to shorter PFS and OS: poorer differential grade, advanced $\mathrm{T}$ stage, $\mathrm{N}$ stage, and TNM stage, as well as higher FA score, and lower PNI (all $P<0.05$ ). Then, we performed multivariate survival analysis by Cox model (Table 5). Results indicated that FA score (score 2, $P<0.001$, hazard ratio $[\mathrm{HR}]=2.868,95 \%$ confidence interval [CI], 1.524-5.395) and TNM stage (for TNM II, $P=0.024$, HR =6.032, 95\% CI, 1.269-28.674; for TNM III, $P=0.001, \mathrm{HR}=6.486,95 \% \mathrm{CI}, 2.064-20.382$ )

Table 3 Characteristics of 182 non-small cell lung cancer patients grouped by FA score and PNI

\begin{tabular}{|c|c|c|c|c|c|c|c|}
\hline \multirow[t]{2}{*}{ Characteristics } & \multicolumn{3}{|c|}{ FA score } & \multirow[t]{2}{*}{$P$-value } & \multicolumn{2}{|l|}{ PNI } & \multirow[t]{2}{*}{$P$-value } \\
\hline & $\begin{array}{l}\text { Score } 0 \\
(N=84)\end{array}$ & $\begin{array}{l}\text { Score I } \\
(N=67)\end{array}$ & $\begin{array}{l}\text { Score } 2 \\
(N=31)\end{array}$ & & $\begin{array}{l}<46.6 \\
(\mathrm{~N}=33)\end{array}$ & $\begin{array}{l}\geq 46.6 \\
(N=149)\end{array}$ & \\
\hline Sex & & & & 0.084 & & & 0.409 \\
\hline Female & 32 & 17 & 6 & & 8 & 47 & \\
\hline Male & 52 & 50 & 25 & & 25 & 102 & \\
\hline Age (years) & & & & 0.203 & & & 0.487 \\
\hline$<60$ & 41 & 24 & 11 & & 12 & 64 & \\
\hline$\geq 60$ & 43 & 43 & 20 & & 21 & 85 & \\
\hline Smoking & & & & $0.005^{*}$ & & & 0.254 \\
\hline Yes & 29 & 33 & 21 & & 18 & 65 & \\
\hline No & 55 & 34 & 10 & & 15 & 84 & \\
\hline Histologic type & & & & 0.087 & & & 0.454 \\
\hline SCC & 25 & 34 & 13 & & 13 & 59 & \\
\hline$A D C$ & 38 & 25 & 12 & & 16 & 59 & \\
\hline Others & 21 & 8 & 6 & & 4 & 31 & \\
\hline Differential grade & & & & $0.002^{*}$ & & & 0.156 \\
\hline Poor & 4 & 7 & 10 & & II & 55 & \\
\hline Middle & 48 & 26 & II & & 15 & 80 & \\
\hline Well & 32 & 24 & 10 & & 7 & 14 & \\
\hline T stage & & & & $<0.00 I^{*}$ & & & $0.030 *$ \\
\hline TI & 45 & 21 & 6 & & 10 & 62 & \\
\hline $\mathrm{T} 2$ & 35 & 33 & 14 & & 13 & 69 & \\
\hline T3 & 4 & 13 & II & & 10 & 18 & \\
\hline$N$ stage & & & & 0.215 & & & 0.107 \\
\hline No & 59 & 40 & 17 & & 17 & 99 & \\
\hline $\mathrm{NI}-3$ & 25 & 27 & 14 & & 16 & 50 & \\
\hline TNM stage & & & & $0.011 *$ & & & 0.107 \\
\hline I & 50 & 32 & 12 & & 13 & 81 & \\
\hline II & 25 & 23 & 7 & & 10 & 45 & \\
\hline III & 9 & 12 & 12 & & 10 & 23 & \\
\hline Adjuvant therapy & & & & 0.837 & & & 0.103 \\
\hline Yes & 44 & 38 & 16 & & 22 & 76 & \\
\hline No & 40 & 29 & 15 & & II & 73 & \\
\hline
\end{tabular}

Note: *Statistically significant values, $P<0.05$.

Abbreviations: FA score, plasma fibrinogen and serum albumin levels score; SCC, squamous cell carcinoma; ADC, adenocarcinoma; PNI, prognostic nutritional index; TNM, tumor, node, and metastases. 
A

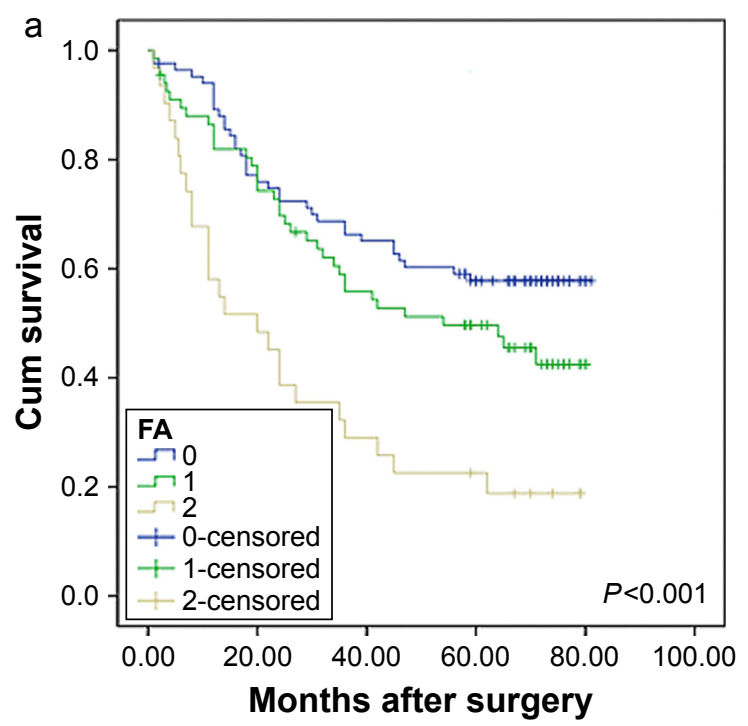

Progression-free survival

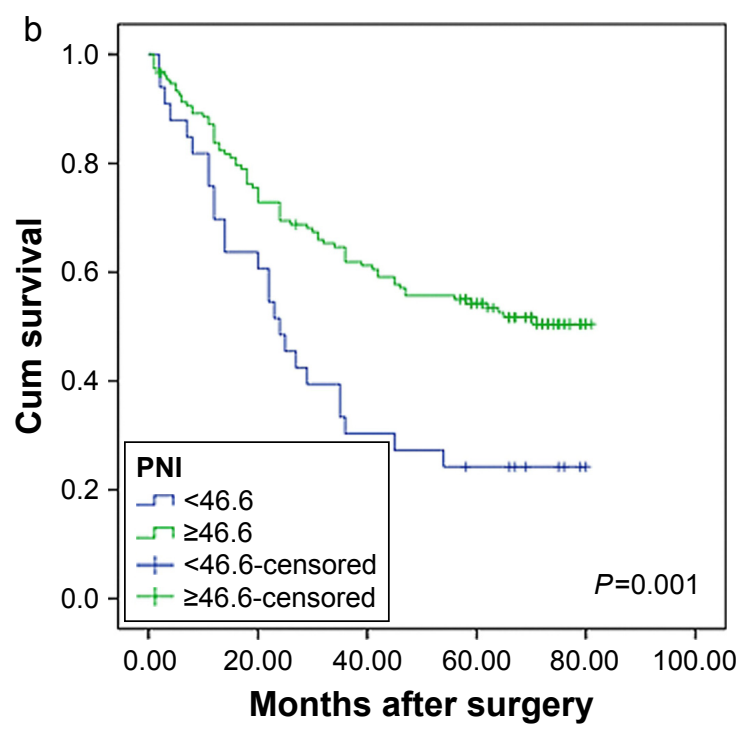

B

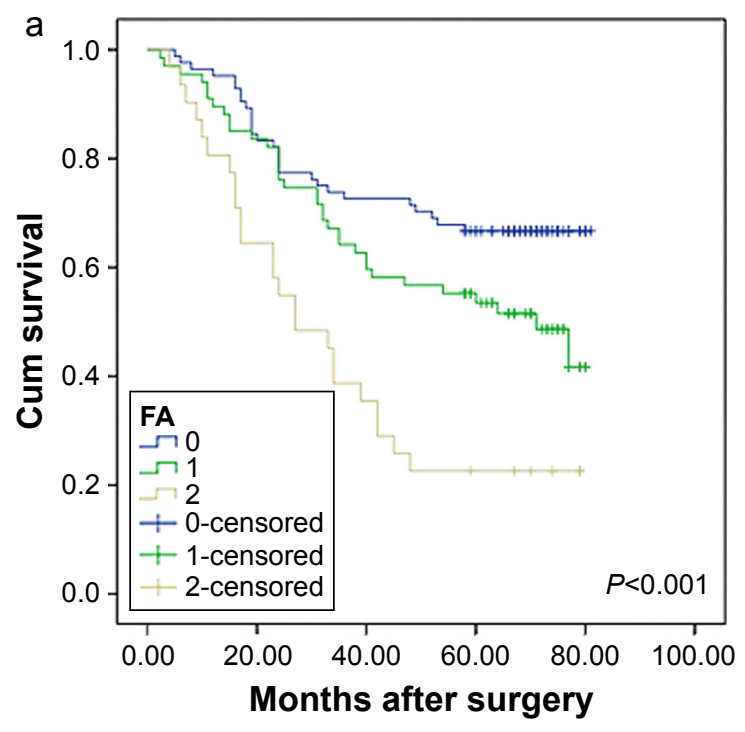

Overall survival

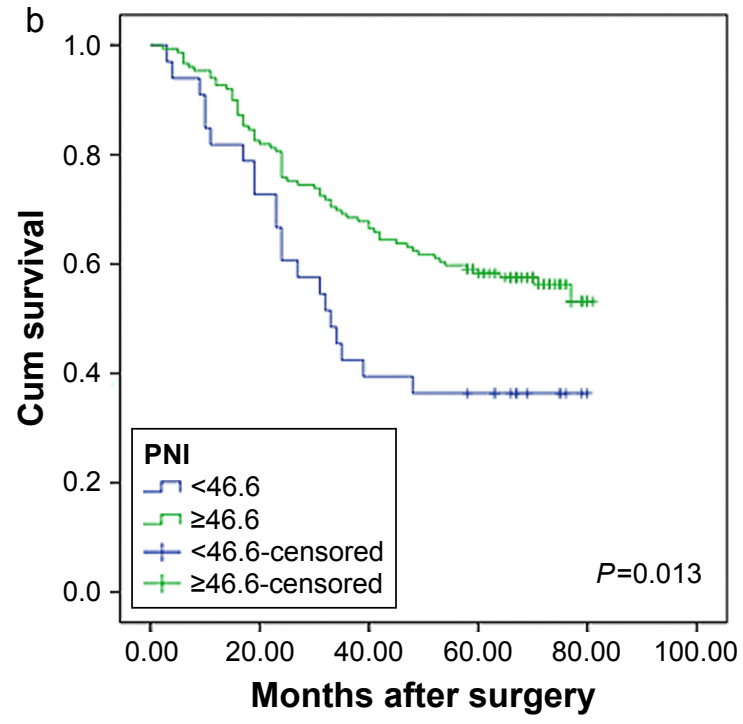

Figure I Kaplan-Meier analysis for progression-free survival (A) and overall survival (B) of non-small cell lung cancer patients based on (a) preoperative FA score and (b) $\mathrm{PNI}$ at the end of follow-up.

Abbreviations: PNI, prognostic nutritional index; Cum, cumulative; FA score, plasma fibrinogen and serum albumin levels score.

were independent factors for OS. As for PFS, FA (score 2, $P=0.003, \mathrm{HR}=2.561,95 \% \mathrm{CI}, 1.390-4.720$ ) was an independent indicator in patients with NSCLC.

\section{Subgroup analysis by histological types of NSCLC}

Considering that clinical outcomes of patients may vary as the histological type changes, our patients were classified into two groups (SCC and ADC groups, and the other types were not analyzed). In the analysis of SCC patients (Figure 2), high FA score was significantly associated with poor PFS $(P=0.022)$ and $\mathrm{OS}(P=0.004)$. Patients with high PNI exhibited superior
PFS ( $P=0.003)$ and OS $(P=0.007)$. For patients with ADC, PFS $(P=0.006)$ and $\mathrm{OS}(P=0.016)$ both dropped significantly when the FA score was 2 . However, PNI showed no statistical relationship with PFS $(P=0.062)$ and $\mathrm{OS}(P=0.466)$ (Figure 3$)$.

\section{Predictive values of FA score and PNI for I-year, 3-year, and 5-year OS}

Survival analyses of 1-year, 3-year, and 5-year OS were included in this study (Figure 4). FA score was associated statistically with the 1-year $(P=0.047), 3$-year $(P=0.001)$, and 5-year $(P<0.001)$ OS. Patients with higher PNI showed superior outcomes for 3-year $(P=0.004)$ and 5-year $(P=0.009)$ 
Table 4 Univariate analysis of survival of non-small cell lung cancer patients treated by surgery

\begin{tabular}{|c|c|c|c|c|c|c|}
\hline \multirow[t]{2}{*}{ Characteristic } & \multicolumn{3}{|l|}{ PFS } & \multicolumn{3}{|l|}{ OS } \\
\hline & $P$-value & HR & $95 \% \mathrm{Cl}$ & $P$-value & HR & $95 \% \mathrm{Cl}$ \\
\hline Female & 0.564 & 0.876 & $0.558-1.374$ & 0.439 & 0.828 & $0.514-1.335$ \\
\hline Age $<60$ (years) & 0.185 & 1.324 & $0.874-2.007$ & 0.161 & 1.370 & $0.882-2.128$ \\
\hline Smoking & 0.966 & 1.009 & $0.676-1.507$ & 0.817 & $1.05 \mathrm{I}$ & $0.688-1.605$ \\
\hline \multicolumn{7}{|l|}{ Histological type } \\
\hline $\mathrm{SCC}$ & & 1.000 & Ref. & & 1.000 & Ref. \\
\hline$A D C$ & 0.051 & 1.565 & $0.998-2.455$ & 0.061 & 1.576 & $0.979-2.536$ \\
\hline Others & 0.548 & 1.192 & $0.67 \mid-2.118$ & 0.647 & 1.153 & $0.626-2.124$ \\
\hline \multicolumn{7}{|l|}{ Differential grade } \\
\hline Poor & & 1.000 & Ref. & & 1.000 & Ref. \\
\hline Middle & $0.009 *$ & 0.458 & $0.255-0.822$ & $0.002^{*}$ & 0.396 & $0.217-0.720$ \\
\hline Well & 0.067 & 0.568 & $0.310-1.041$ & $0.033^{*}$ & 0.512 & $0.277-0.946$ \\
\hline \multicolumn{7}{|l|}{ T stage } \\
\hline TI & & 1.000 & Ref. & & 1.000 & Ref. \\
\hline T2 & 0.116 & 1.447 & $0.9|3-2.29|$ & 0.032 & 1.739 & I.048-2.885 \\
\hline T3 & $<0.001 *$ & 2.594 & I.485-4.532 & $<0.001 *$ & 3.561 & $1.986-6.385$ \\
\hline $\mathrm{N}$ stage: $\mathrm{N} 0 / \mathrm{NI}-3$ & $0.027^{*}$ & 1.584 & $1.052-2.383$ & $0.024 *$ & 1.640 & $1.069-2.518$ \\
\hline \multicolumn{7}{|l|}{ TNM stage } \\
\hline 1 & & 1.000 & Ref. & & 1.000 & Ref. \\
\hline II & 0.337 & 1.258 & $0.788-2.007$ & 0.112 & 1.496 & $0.911-2.456$ \\
\hline III & $0.003^{*}$ & 2.167 & $1.297-3.620$ & $<0.001 *$ & 2.605 & $1.527-4.445$ \\
\hline Treatment regimens: surgery alone & 0.482 & 0.865 & $0.578-1.295$ & 0.177 & 0.743 & $0.482-1.144$ \\
\hline \multicolumn{7}{|l|}{ FA score } \\
\hline 0 & & 1.000 & Ref. & & 1.000 & Ref. \\
\hline I & 0.143 & 1.147 & $0.889-2.257$ & $0.046^{*}$ & 1.664 & $1.009-2.745$ \\
\hline 2 & $<0.001 *$ & 3.119 & $1.86 \mid-5.229$ & $<0.001 *$ & 3.505 & $2.024-6.069$ \\
\hline $\mathrm{PNI} \geq 46.6$ & $0.00 I^{*}$ & 0.475 & $0.300-0.75$ I & $0.016^{*}$ & 0.544 & $0.332-0.89 \mid$ \\
\hline
\end{tabular}

Note: *Statistically significant values, $P<0.05$.

Abbreviations: PFS, progression-free survival; OS, overall survival; HR, hazard ratio; Cl, confidence interval; Ref., reference; SCC, squamous cell carcinoma; ADC, adenocarcinoma; FA score, plasma fibrinogen and serum albumin levels score; PNI, prognostic nutritional index; TNM, tumor, node, and metastases.

OS, while no association was found between PNI and 1-year $(P=0.069)$ OS.

\section{ROC curves of FA score and PNI for predicting survival outcomes}

ROC curve analyses of FA score and PNI were performed for PFS and OS prediction (Figure 5). The area under the ROC curve (AUC) was 0.636 for FA score $(P=0.001,95 \%$
CI, 0.556-0.717) and 0.584 for PNI $(P=0.051,95 \% \mathrm{CI}$, $0.501-0.666)$ in the analysis on PFS. For OS, the AUC was 0.662 for FA score $(P<0.001,95 \% \mathrm{CI}, 0.583-0.742)$ and 0.560 for PNI $(P=0.166,95 \%$ CI, 0.476-0.644).

\section{Discussion}

Recently, several prognostic factors have been reported in NSCLC patients, including neutrophil to lymphocyte ratio,

Table 5 Multivariate analysis of survival of non-small cell lung cancer patients treated by surgery

\begin{tabular}{|c|c|c|c|c|c|c|}
\hline \multirow[t]{2}{*}{ Characteristic } & \multicolumn{3}{|l|}{ PFS } & \multicolumn{3}{|l|}{ OS } \\
\hline & $P$-value & HR & $95 \% \mathrm{Cl}$ & $P$-value & HR & $95 \% \mathrm{Cl}$ \\
\hline \multicolumn{7}{|l|}{ Differential grade } \\
\hline Poor & & 1.000 & Ref. & & 1.000 & Ref. \\
\hline Middle & 0.467 & 1.650 & $0.428-6.37 \mid$ & 0.055 & 3.344 & $0.976-11.462$ \\
\hline Well & 0.550 & 1.368 & $0.489-3.824$ & 0.730 & 0.818 & $0.262-2.558$ \\
\hline \multicolumn{7}{|l|}{ TNM stage } \\
\hline 1 & & 1.000 & Ref. & & 1.000 & Ref. \\
\hline II & 0.580 & $\mathrm{I} .503$ & $0.355-6.355$ & $0.024 *$ & 6.032 & I.269-28.674 \\
\hline III & 0.128 & 2.654 & $0.755-9.324$ & $0.001 *$ & 6.486 & $2.064-20.382$ \\
\hline \multicolumn{7}{|l|}{ FA score } \\
\hline 0 & & 1.000 & Ref. & & 1.000 & Ref. \\
\hline 1 & 0.232 & $\mathrm{I} .353$ & $0.824-2.221$ & 0.185 & $\mathrm{I} .427$ & $0.844-2.415$ \\
\hline 2 & $0.003 *$ & 2.561 & $1.390-4.720$ & $0.001 *$ & 2.868 & $1.524-5.395$ \\
\hline $\mathrm{PNI} \geq 46.6$ & 0.164 & 0.694 & $0.415-1.160$ & 0.476 & 0.820 & $0.476-1.415$ \\
\hline
\end{tabular}

Note: *Statistically significant values, $P<0.05$.

Abbreviations: PFS, progression-free survival; OS, overall survival; $\mathrm{HR}$, hazard ratio; $\mathrm{Cl}$, confidence interval; Ref., reference; FA score, plasma fibrinogen and serum albumin levels score; PNI, prognostic nutritional index; TNM, tumor, node, and metastases. 
A

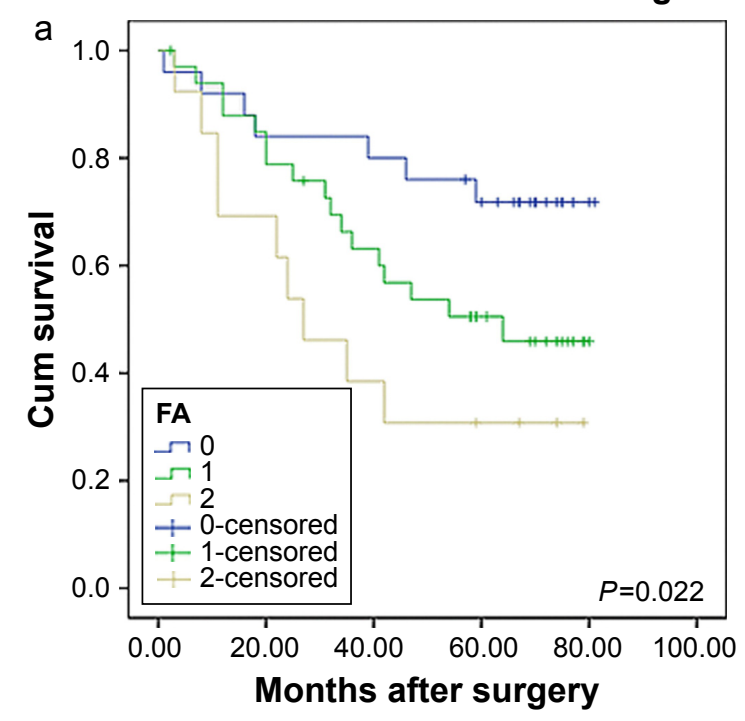

Progression-free survival

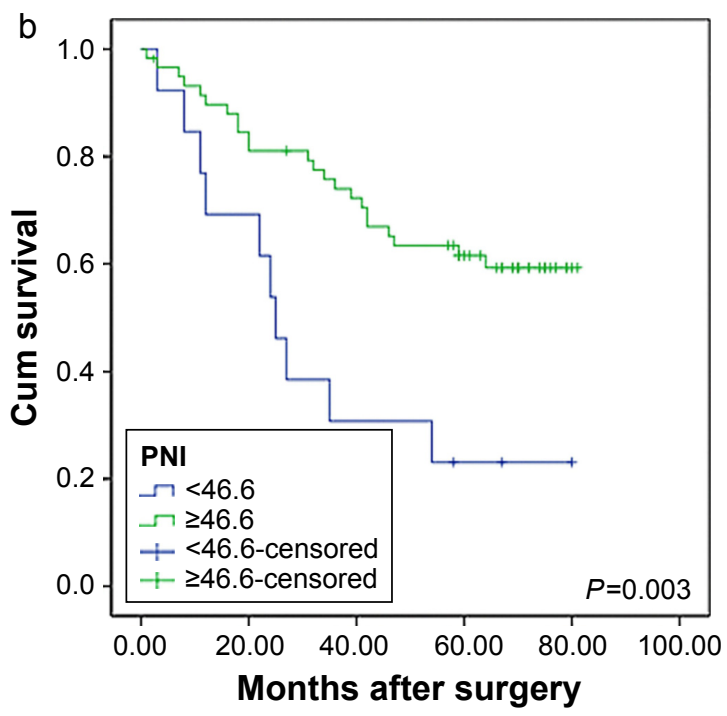

B

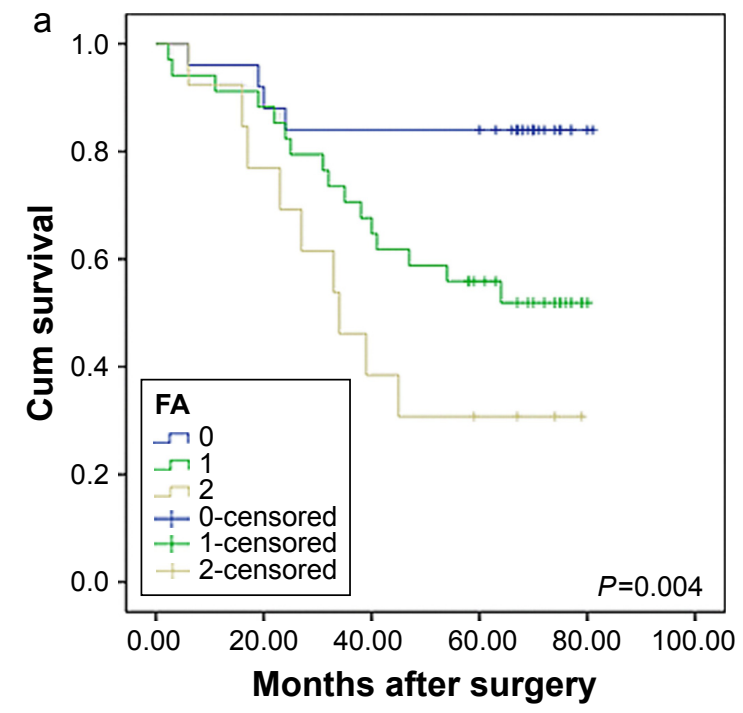

Overall survival

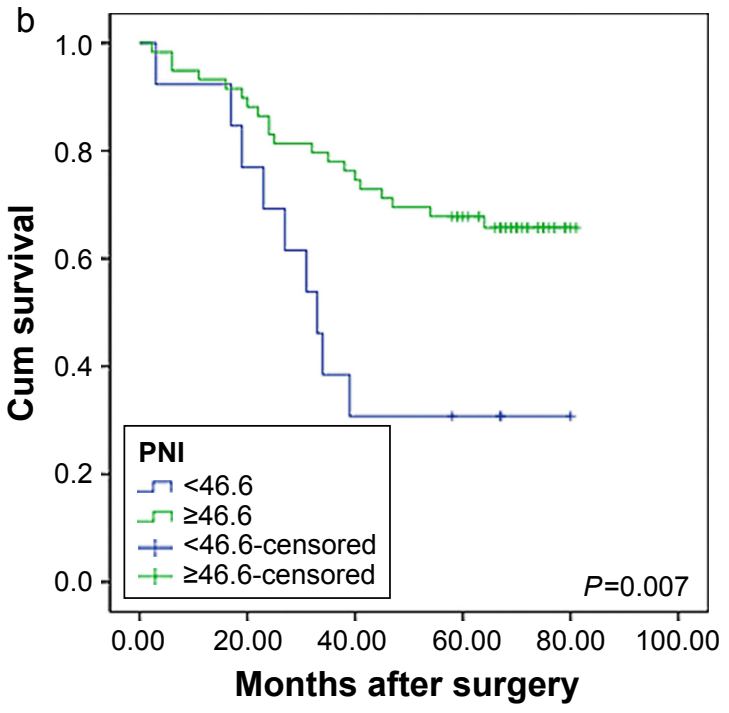

Figure 2 Kaplan-Meier analysis for progression-free survival (A) and overall survival (B) in squamous cell carcinoma patients according to (a) preoperative FA score and (b) PNI.

Abbreviations: PNI, prognostic nutritional index; Cum survival, cumulative survival; FA score, plasma fibrinogen and serum albumin levels score.

lymphocyte to monocyte ratio, serum albumin, fibrinogen, and others. ${ }^{12,14,18,21,22}$ In the present study, the clinical values of preoperative FA score and PNI were investigated in patients with resectable NSCLC. High FA score was related to smoking status, poor differential grade, and advanced $\mathrm{T}$ stage and TNM stage. FA score acted as an independent predictive factor for PFS and OS in patients with NSCLC. Low PNI was also associated with advanced T stage. PNI showed a statistical relationship with both PFS and OS, but was not an independent indicator according to the multivariate analysis. In addition, FA score and PNI exhibited different values according to different histological types and different survival times. These results reinforced that FA score and PNI could provide abundant information about the clinical prognosis of NSCLC patients, and FA score might be a more promising prognostic indicator, compared to PNI.

The roles of malnutrition and inflammation in regulating carcinogenesis, tumor progression, and metastasis have become the hot spot in cancer research. ${ }^{1,5,23}$ Low serum albumin could represent the compromised nutritional status of the host, as well as the response of systemic inflammation. ${ }^{24}$ Studies demonstrated that hypoalbuminemia was associated with poor prognosis and decreased survival in various malignancies. ${ }^{24-26}$ Tanriverdi et al reported that low serum albumin could predict poor prognosis in NSCLC patients, and reflects reduced response rate to first-line therapy. ${ }^{14}$ Studies found the association between hypoalbuminemia and poor clinical outcomes in patients with NSCLC. ${ }^{27,28}$ In our analysis, 
A

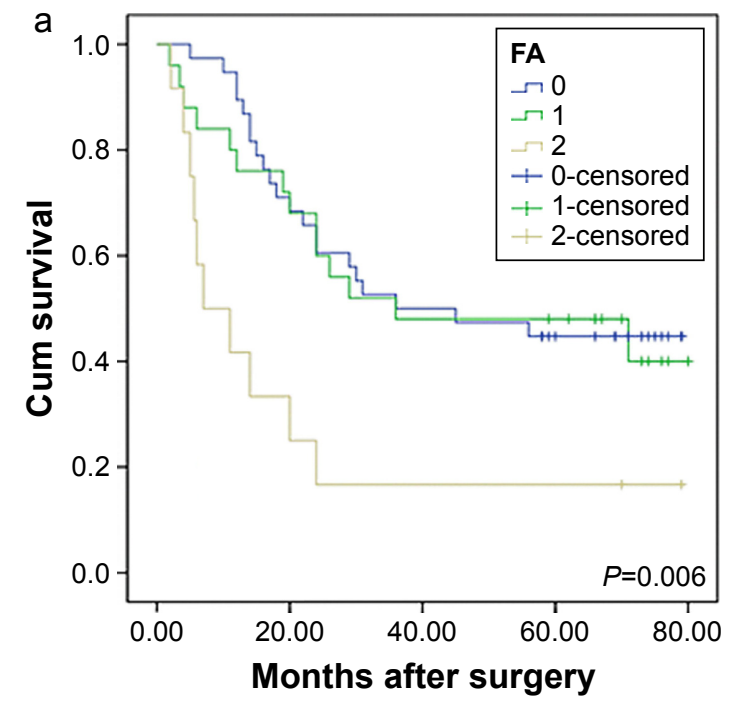

Progression-free survival

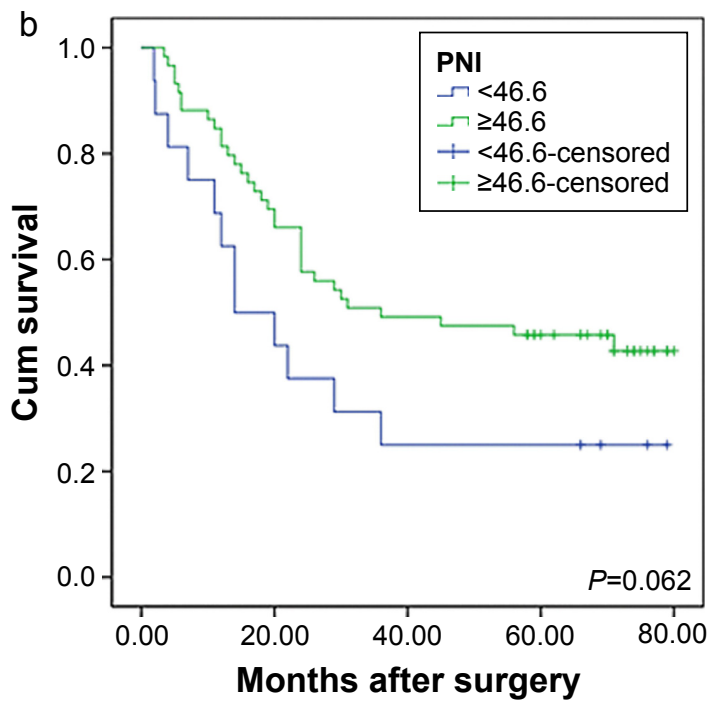

B

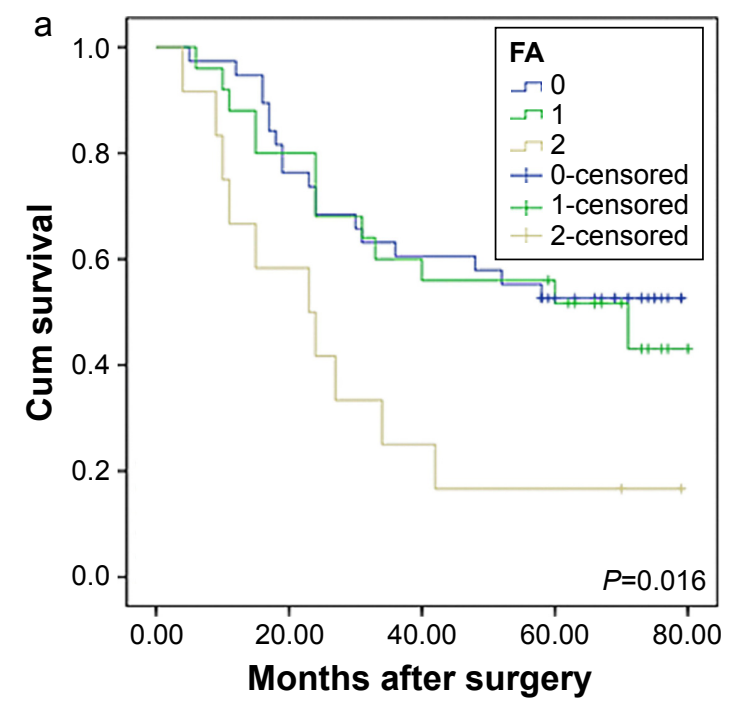

Overall survival

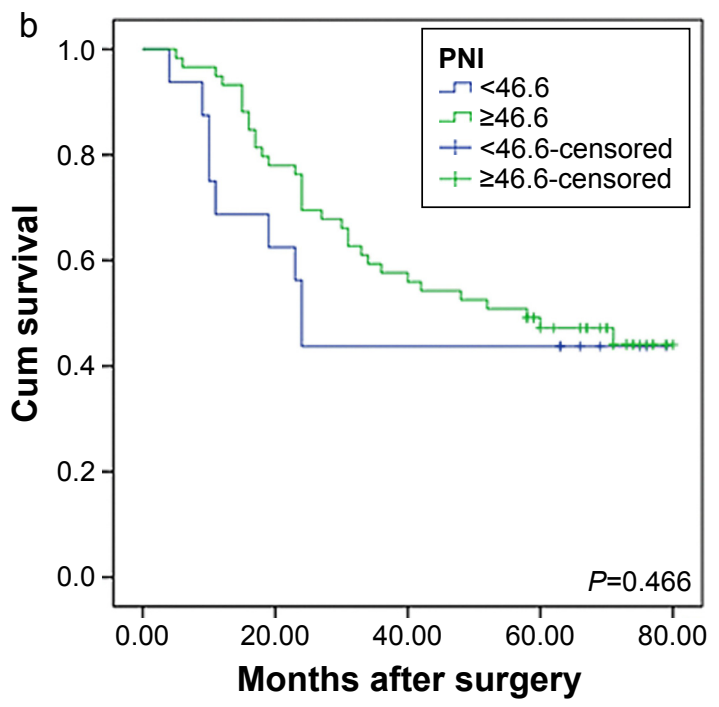

Figure 3 Kaplan-Meier analysis for progression-free survival (A) and overall survival (B) in adenocarcinoma patients according to (a) preoperative FA score and (b) PNI. Abbreviations: PNI, prognostic nutritional index; Cum survival, cumulative survival; FA score, plasma fibrinogen and serum albumin levels score.

low preoperative albumin level showed a statistical relation with poor differential grade and advanced tumor stage, which was consistent with other studies.

Activated coagulation and fibrinolysis are commonly related to tumor invasion and metastasis. Studies proved that elevated concentration of platelet count, D-dimer, and antithrombin III content had a strong association with a worse prognosis in NSCLC patients. ${ }^{29-31}$ Recent studies revealed that serum fibrinogen showed a correlation with prognosis in different cancers. ${ }^{32,33}$ Elevated fibrinogen level was found to be associated with poor prognosis acting as a predictive biomarker in NSCLC patients. ${ }^{11,12}$ High fibrinogen had a relationship with poor differential grade, and advanced $\mathrm{T}$ stage,
$\mathrm{N}$ stage, and TNM stage. It is reasonable to adopt the FA score as a prognostic scoring system in NSCLC patients. As a combined indicator, FA score could represent nutritional status, inflammation, and the coagulation system of a patient.

FA score was observed to have an association with tumor invasion depth, lymph node metastasis, and postoperative survival in esophageal cancer patients. ${ }^{15}$ In our cohort, the FA score showed a statistical relation with smoking status, differential grade, T stage, and TNM stage. FA score 2 represented aggressive tumor phenotypes and unfavorable prognosis, relative to FA score 0 . Considering the association of FA score and smoking status in this study, our subgroup analysis found that FA score was related to survival both in smokers $(P=0.011)$ 
A

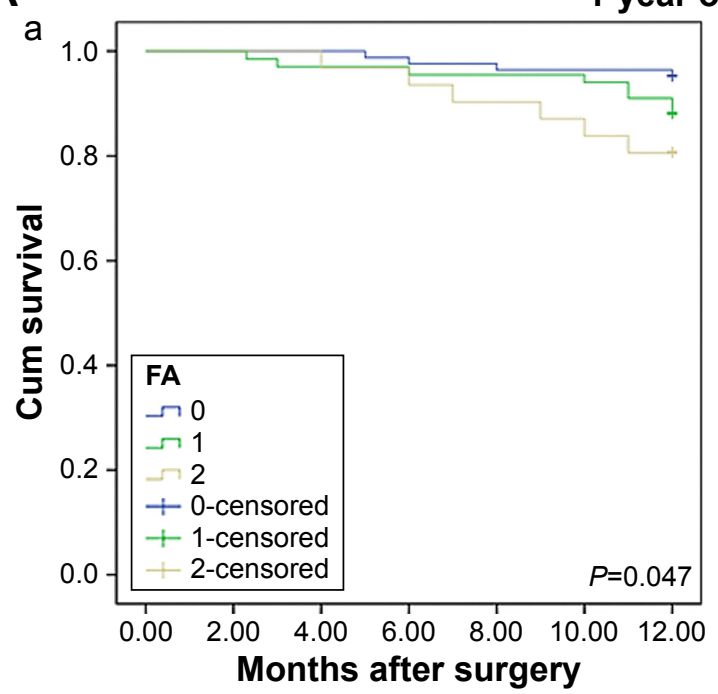

1-year overall survival

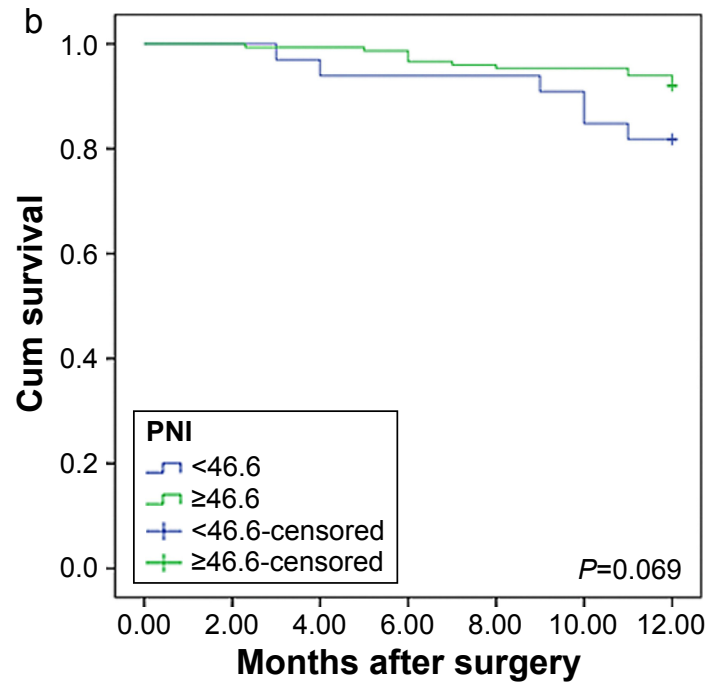

B
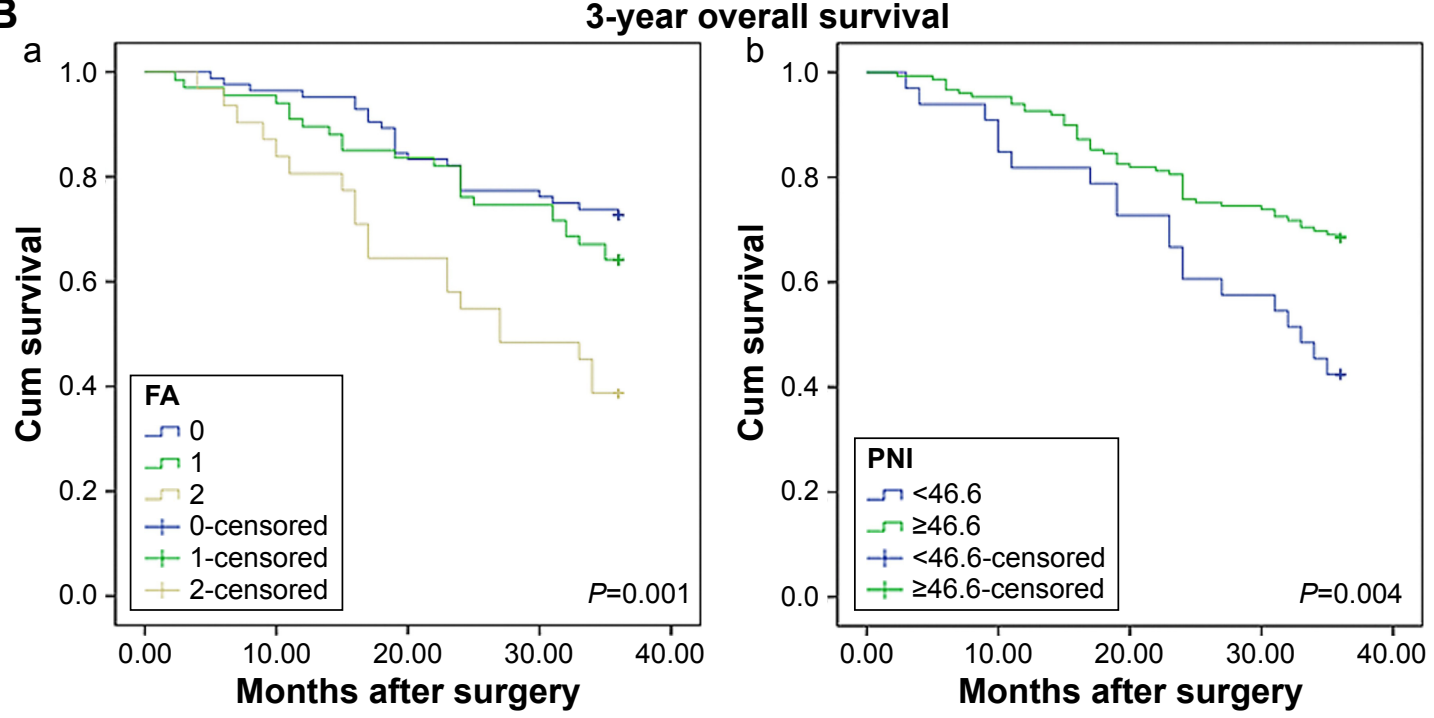

C
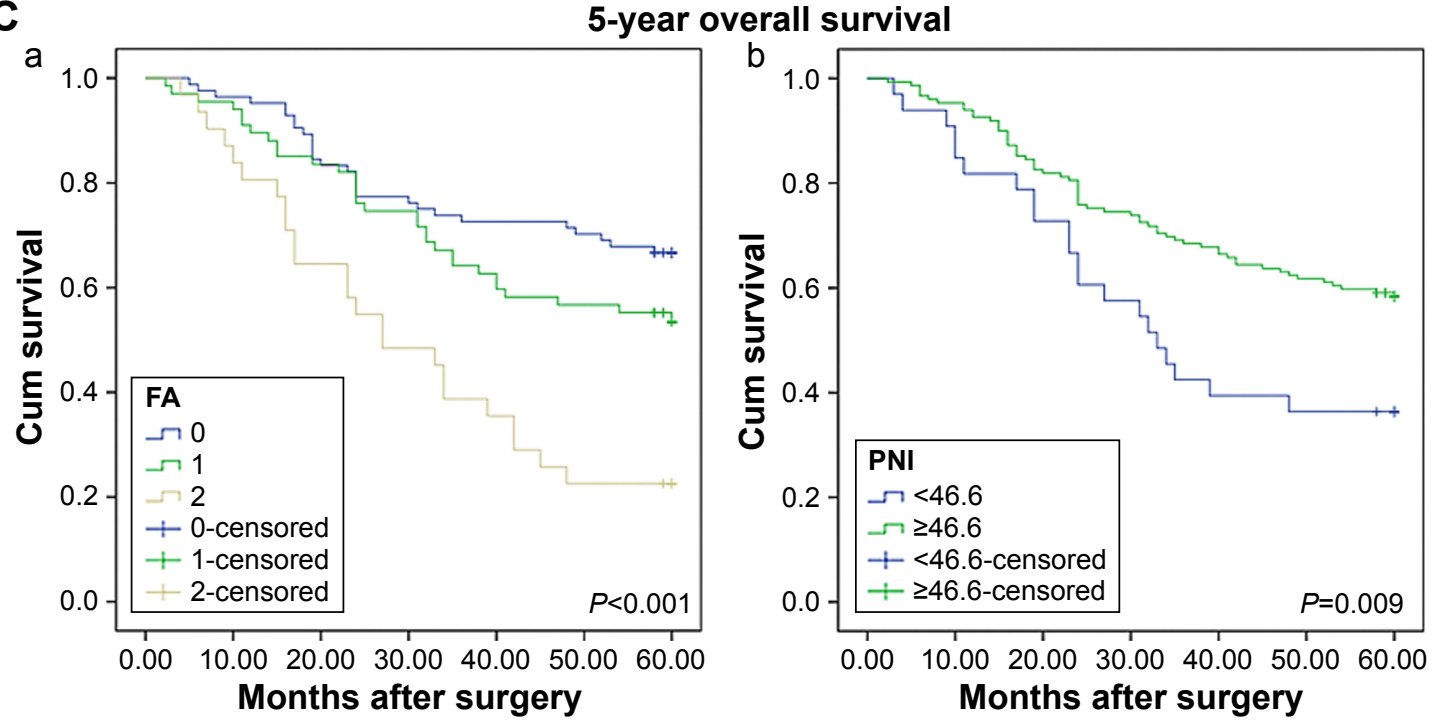

Figure 4 Kaplan-Meier analysis for I-year (A), 3-year (B), and 5-year (C) overall survival of I82 non-small cell lung cancer patients according to (a) preoperative FA score and (b) PNI.

Abbreviations: PNI, prognostic nutritional index; Cum survival, cumulative survival; FA score, plasma fibrinogen and serum albumin levels score. 

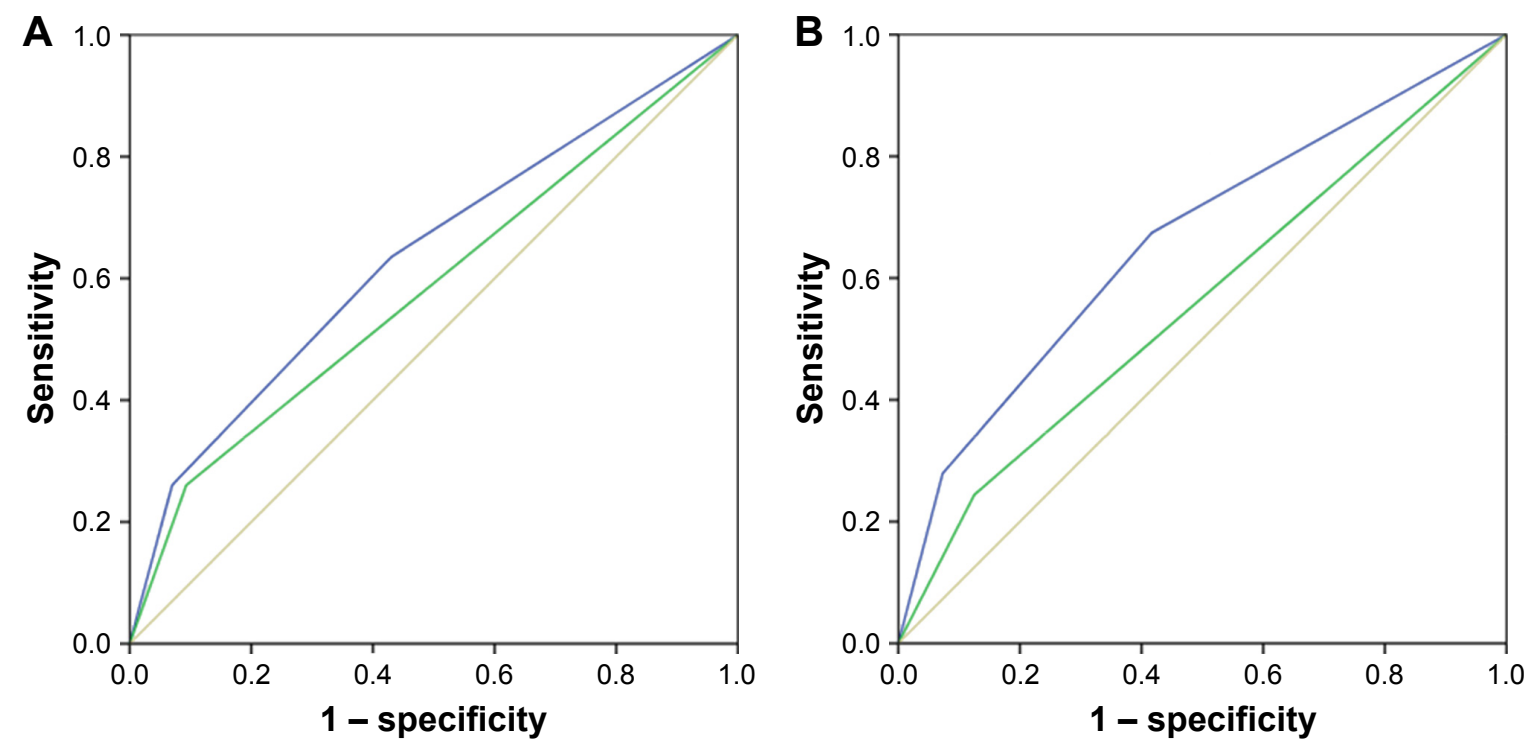

- FA - PNI - Reference line

Figure 5 ROC curve analysis of FA score and PNI for progression-free survival (A) and overall survival (B) prediction.

Abbreviations: PNI, prognostic nutritional index; ROC, receiver operating characteristic; FA score, plasma fibrinogen and serum albumin levels score.

and in nonsmokers $(P<0.001)$. Furthermore, FA score was associated with PFS and OS in both SCC and ADC according to our analysis. Patients with neoadjuvant treatments were excluded considering the influence of preoperative treatment on clinical outcomes, but 84 patients with postoperative treatment were still included in the analysis. Then, we assessed the association of postoperative treatment and PFS $(P=0.482)$ and $\mathrm{OS}(P=0.177)$, but no positive results were found. Among 98 patients without postoperative therapy, FA score was still statistically related to PFS and OS (both $P=0.001$ ). Patients with score 0 had a median OS of 67.0 months, while it was 27.0 months when patients were in the score 2 group. The mortality of patients according to a score of 0,1 , and 2 was $33.3 \%, 50.7 \%$, and $77.4 \%(P<0.001)$, respectively.

Low albumin commonly reflects malnutrition, which could impair anatomic barriers, immunity, and other defense mechanisms. ${ }^{34}$ Fibrinogen is involved in the connection between matrix and tumor cells. It could act as a scaffold binding with growth factors, including vascular endothelial growth factor and fibroblast growth factor-2, ${ }^{35,36}$ which promotes adhesion, proliferation, and migration of tumor cells. Moreover, fibrinogen deposition facilitates the formation of thrombin by enhancing the interaction of tumor cells and platelets, which protects tumor cells from natural killers. ${ }^{37}$ Palumbo et al revealed that the formation of pulmonary metastases could be inhibited when circulating fibrinogen was absent in mice models. ${ }^{38}$ The results can help explain our findings of FA score in NSCLC patients.
PNI was reported to exhibit an association with tumor prognosis. Studies have confirmed that NSCLC patients with low PNI experienced poor clinical outcomes, but the optimal cutoff value was controversial. ${ }^{18,19,21}$ Besides albumin, the predictive value of PNI stems from lymphocyte partially. Lymphocytes play an important role in inducing cytotoxic immune responses and suppressing tumor cell proliferation and invasion. ${ }^{39,40}$ However, another study observed that elevated $\mathrm{CD}^{+}{ }^{+} \mathrm{T}$ lymphocyte infiltration into tumor was correlated with poor outcome in prostate cancer patients. ${ }^{41}$ In our analysis, patients with low lymphocyte count tended to develop lymph node metastasis and demonstrated advanced TNM stage. We set the cutoff value of PNI as 46.6, and found that patients with PNI $<46.6$ had advanced T stage. PFS and OS would be longer if patients had a high PNI. We found that PFS and OS had no significant difference between two groups of PNI in patients with ADC, which might partially be explained by the different biological features between SCC and ADC. As Black et al elaborated, an enrichment of regulatory $\mathrm{T}$ lymphocytes (Tregs) existed in lung ADC tissues, and was associated with poor outcomes. ${ }^{42}$ This may diminish prognostic values of PNI in patients with ADC.

In the multivariate analysis, FA score was an independent predictive factor for PFS and OS while PNI was not. Our analysis of the 1-year, 3-year, and 5-year OS revealed that PNI was not suitable for predicting short-term survival in NSCLC patients. ROC curves of FA score showed that the 
AUC was $0.636(P=0.001)$ for PFS and $0.662(P<0.001)$ for OS, which were superior to PNI. These suggest that the FA score could provide more prognostic information, being a more accurate predictor than PNI.

This research is limited to a retrospective single-center cohort, and a small sample was enrolled. We only conducted a subgroup analysis including SCC and ADC, and other pathological types were excluded because of the small sample size. In addition, the cutoff levels were calculated by ROC curves, and it was unclear whether other cutoff values were more valuable. Considering this, our study confirmed that FA score was a potential independent prognostic predictor in NSCLC patients undergoing surgical treatment. Multicentric prospective studies with large samples need to be carried out in the future.

\section{Conclusion}

In general, the nutrition and coagulation-based FA score might be a more promising prognostic predictor than PNI in NSCLC patients who undergo surgical therapy. Measurements of fibrinogen and albumin were carried out at low cost, were less traumatic, and were easily accessible in clinical practice. Thus, the FA score could serve as a biomarker for prognosis in NSCLC patients with pneumonectomy. This systemic score can facilitate doctors' selection of patients who may need to accept more adjuvant therapies and more frequent follow-up, which are beneficial for personalized treatment in NSCLC.

\section{Acknowledgment}

This research was supported by the National Natural Science Foundation of China (no 81572958), Natural Science Foundation of Shandong Province (ZR2015HQ024), and Science and Technology Development Planning Project of Shandong Province (2014GSF118058).

\section{Disclosure}

The authors report no conflicts of interest in this work.

\section{References}

1. Torre LA, Bray F, Siegel RL, Ferlay J, Lortet-Tieulent J, Jemal A. Global cancer statistics, 2012. CA Cancer J Clin. 2015;65(2):87-108.

2. Seer.cancer.gov [homepage on the Internet]. SEER cancer statistics review, 1975-2012 (based on November 2014 SEER data submission). Bethesda, MD: National Cancer Institute; 2015 [cited February 8, 2016]. Available from: http://seer.cancer.gov/csr/1975_2012/. Accessed January $15,2017$.

3. Seer.cancer.gov [homepage on the Internet]. SEER cancer statistics factsheets: lung and bronchus cancer. Bethesda, MD: National Cancer Institute; 2015 [cited February 8, 2016]. Available from: http://seer. cancer.gov/statfacts/html/lungb.html. Accessed January 15, 2017.
4. Ilhan-Mutlu A, Starlinger P, Perkmann T, Schoppmann SF, Preusser M, Birner P. Plasma fibrinogen and blood platelet counts are associated with response to neoadjuvant therapy in esophageal cancer. Biomark Med. 2015;9(4):327-335.

5. Sun KY, Xu JB, Chen SL, et al. Novel immunological and nutritionalbased prognostic index for gastric cancer. World J Gastroenterol. 2015; 21(19):5961-5971.

6. Nozoe T, Ninomiya M, Maeda T, Matsukuma A, Nakashima H, Ezaki T. Prognostic nutritional index: a tool to predict the biological aggressiveness of gastric carcinoma. Surg Today. 2010;40(5):440-443.

7. Yamaguchi T, Yamamoto Y, Yokota S, Nakagawa M, Ito M, Ogura T. Involvement of interleukin-6 in the elevation of plasma fibrinogen levels in lung cancer patients. Jpn J Clin Oncol. 1998;28(12):740-744.

8. Tennent GA, Brennan SO, Stangou AJ, O'Grady J, Hawkins PN, Pepys MB. Human plasma fibrinogen is synthesized in the liver. Blood. 2007;109(5):1971-1974.

9. Miki C, Konishi N, Ojima E, Hatada T, Inoue Y, Kusunoki M. $\mathrm{C}$-reactive protein as a prognostic variable that reflects uncontrolled up-regulation of the IL-1-IL-6 network system in colorectal carcinoma. Dig Dis Sci. 2004;49(6):970-976.

10. Jiang H, Li J, Shi S, et al. Value of fibrinogen and D-dimer in predicting recurrence and metastasis after radical surgery for non-small cell lung cancer. Med Oncol. 2014;31(7):22.

11. Kim KH, Park TY, Lee JY, et al. Prognostic significance of initial platelet counts and fibrinogen level in advanced non-small cell lung cancer. J Korean Med Sci. 2014;29(4):507.

12. Sheng L, Luo M, Sun X, Lin N, Mao W, Su D. Serum fibrinogen is an independent prognostic factor in operable nonsmall cell lung cancer. Int J Cancer. 2013;133(11):2720-2725.

13. Fiala $\mathrm{O}$, Pesek M, Finek J, et al. Serum albumin is a strong predictor of survival in patients with advanced-stage non-small cell lung cancer treated with erlotinib. Neoplasma. 2016;63(3):471-476.

14. Tanriverdi O, Avci N, Oktay E, et al. Pretreatment serum albumin level is an independent prognostic factor in patients with stage IIIB non-small cell lung cancer: a study of the Turkish Descriptive Oncological Researches Group. Asian Pac J Cancer Prev. 2015;16(14): 5971-5976.

15. Matsuda S, Takeuchi H, Kawakubo H, et al. Cumulative prognostic scores based on plasma fibrinogen and serum albumin levels in esophageal cancer patients treated with transthoracic esophagectomy: comparison with the Glasgow prognostic score. Ann Surg Oncol. 2015;22: 302-310.

16. Nozoe T, Kimura Y, Ishida M, Saeki H, Korenaga D, Sugimachi K. Correlation of pre-operative nutritional condition with post-operative complications in surgical treatment for oesophageal carcinoma. Eur $J$ Surg Oncol. 2002;28(4):396-400.

17. Pinato DJ, North BV, Sharma R. A novel, externally validated inflammationbased prognostic algorithm in hepatocellular carcinoma: the prognostic nutritional index (PNI). Br J Cancer. 2012;106(8):1439-1445.

18. Shimizu K, Okita R, Saisho S, Maeda A, Nojima Y, Nakata M. Preoperative neutrophil/lymphocyte ratio and prognostic nutritional index predict survival in patients with non-small cell lung cancer. World $J$ Surg Oncol. 2015;13(1):291.

19. Shoji F, Morodomi Y, Akamine T, et al. Predictive impact for postoperative recurrence using the preoperative prognostic nutritional index in pathological stage I non-small cell lung cancer. Lung Cancer. 2016; 98:15-21.

20. Hong S, Zhou T, Fang W, et al. The prognostic nutritional index (PNI) predicts overall survival of small-cell lung cancer patients. Tumor Biol. 2015;36(5):3389-3397.

21. Mori S, Usami N, Fukumoto K, et al. The significance of the prognostic nutritional index in patients with completely resected non-small cell lung cancer. PLos One. 2015;10(9):e136897.

22. Song Y, Wang L, Hong Y, et al. Lymphocyte to monocyte ratio is associated with response to first-line platinum-based chemotherapy and prognosis of early-stage non-small cell lung cancer patients. Tumor Biol. 2016;37(4):5285-5293. 
23. Zitvogel L, Tesniere A, Kroemer G. Cancer despite immunosurveillance: immunoselection and immunosubversion. Nat Rev Immunol. 2006; 6(10):715-727.

24. Crumley AB, Stuart RC, McKernan M, McMillan DC. Is hypoalbuminemia an independent prognostic factor in patients with gastric cancer? World J Surg. 2010;34(10):2393-2398.

25. Asher V, Lee J, Bali A. Preoperative serum albumin is an independent prognostic predictor of survival in ovarian cancer. Med Oncol. 2012; 29(3):2005-2009.

26. Ku JH, Kim M, Choi WS, Kwak C, Kim HH. Preoperative serum albumin as a prognostic factor in patients with upper urinary tract urothelial carcinoma. Int Braz J Urol. 2014;40(6):753-762.

27. Sun H, Hu P, Shen H, et al. Albumin and neutrophil combined prognostic grade as a new prognostic factor in non-small cell lung cancer: results from a large consecutive cohort. PLos One. 2015;10(12):e144663.

28. Espinosa E, Feliu J, Zamora P, et al. Serum albumin and other prognostic factors related to response and survival in patients with advanced nonsmall cell lung cancer. Lung Cancer. 1995;12(1-2):67-76.

29. Komurcuoglu B, Ulusoy S, Gayaf M, Guler A, Ozden E. Prognostic value of plasma D-dimer levels in lung carcinoma. Tumori. 2011;97(6): 743-748.

30. Unsal E, Atalay F, Atikcan S, Yilmaz A. Prognostic significance of hemostatic parameters in patients with lung cancer. Respir Med. 2004; 98(2):93-98.

31. Gonzalez BF, Garcia PJ, Moldes RM, et al. Platelet count: association with prognosis in lung cancer. Med Oncol. 2010;27(2):357-362.

32. Takeuchi H, Ikeuchi S, Kitagawa Y, et al. Pretreatment plasma fibrinogen level correlates with tumor progression and metastasis in patients with squamous cell carcinoma of the esophagus. J Gastroenterol Hepatol. 2007;22(12):2222-2227.

33. Sun Z. Prognostic significance of preoperative fibrinogen in patients with colon cancer. World J Gastroenterol. 2014;20(26):8583.
34. Ataseven B, du Bois A, Reinthaller A, et al. Pre-operative serum albumin is associated with post-operative complication rate and overall survival in patients with epithelial ovarian cancer undergoing cytoreductive surgery. Gynecol Oncol. 2015;138(3):560-565.

35. Sahni A, Simpson-Haidaris PJ, Sahni SK, Vaday GG, Francis CW. Fibrinogen synthesized by cancer cells augments the proliferative effect of fibroblast growth factor-2 (FGF-2). J Thromb Haemost. 2008;6(1): 176-183.

36. Sahni A, Francis CW. Vascular endothelial growth factor binds to fibrinogen and fibrin and stimulates endothelial cell proliferation. Blood. 2000;96(12):3772-3778.

37. Zheng S, Shen J, Jiao Y, et al. Platelets and fibrinogen facilitate each other in protecting tumor cells from natural killer cytotoxicity. Cancer Sci. 2009;100(5):859-865.

38. Palumbo JS, Kombrinck KW, Drew AF, et al. Fibrinogen is an important determinant of the metastatic potential of circulating tumor cells. Blood. 2000;96(10):3302-3309.

39. Mantovani A, Allavena P, Sica A, Balkwill F. Cancer-related inflammation. Nature. 2008;454(7203):436-444.

40. Coussens LM, Werb Z. Inflammation and cancer. Nature. 2002; 420(6917):860-867.

41. McArdle PA, Canna K, McMillan DC, McNicol AM, Campbell R, Underwood MA. The relationship between T-lymphocyte subset infiltration and survival in patients with prostate cancer. Br J Cancer. 2004; 91:541-543.

42. Black CC, Turk MJ, Dragnev K, Rigas JR. Adenocarcinoma contains more immune tolerance regulatory T-cell lymphocytes (versus squamous carcinoma) in non-small-cell lung cancer. Lung. 2013;191(3): 265-270.

43. Detterbeck FC, Boffa DJ, Tanoue LT. The new lung cancer staging system. Chest. 2009;136(1):260-271.
OncoTargets and Therapy

\section{Publish your work in this journal}

OncoTargets and Therapy is an international, peer-reviewed, open access journal focusing on the pathological basis of all cancers, potential targets for therapy and treatment protocols employed to improve the management of cancer patients. The journal also focuses on the impact of management programs and new therapeutic agents and protocols on

\section{Dovepress}

patient perspectives such as quality of life, adherence and satisfaction The manuscript management system is completely online and includes a very quick and fair peer-review system, which is all easy to use. Visit http://www.dovepress.com/testimonials.php to read real quotes from published authors. 